\title{
AVENIDA LIBERDADE: INFLUÊNCIAS PARA A ESTRUTURAÇÃO DO ESPAÇO URBANO DE BAYEUX - PB
}

\author{
Maiara Ateciene dos Santos Belo ${ }^{1}$
}

Doralice Sátyro Maia ${ }^{2}$

\section{RESUMO}

A Avenida Liberdade, localizada no município de Bayeux, consolidou-se como eixo estruturador da expansão urbana da cidade, com ênfase no período compreendido entre as décadas de 1960 a 1980. Esse período é marcado pela emancipação política do município e por intervenções de grupos da iniciativa privada que, aliados a ações governamentais específicas, fizeram dessa Avenida uma área atrativa para a concentração industrial e, posteriormente, comercial, gerando alterações na sua maneira de uso, o que a fez perder sua característica eminentemente residencial. Devido a essas alterações, ocorreu a necessidade do deslocamento da população que residia ao longo da avenida que, juntamente com grupos de pessoas vindos de várias regiões do Estado em busca de inserção nos novos postos de trabalho, passaram a habitar outras áreas da cidade, ocasionando, entre outros fatores, a sua expansão territorial. Dessa maneira, as transformações ocorridas nessa Avenida acarretaram uma nova configuração e estruturação para o município de Bayeux. Assim, entender como as intervenções realizadas na Avenida Liberdade transformaram a estrutura urbana do município é o objetivo desta pesquisa.

PALAVRAS-CHAVE: Avenida Liberdade, Bayeux-PB, Expansão Urbana.

\section{AVENIDA LIBERDADE: INFLUENCES TO THE STRUCTURE OF THE URBAN SPACE BAYEUX - PB}

\begin{abstract}
ABSCTRACT
Liberdade Avenue located in Bayeux city, established itself as a structural axis of its urban expansion, with emphasis on the period between the decades 1960-1980. This period is marked by the city's political emancipation and interventions by groups of private sector which, together with specific government actions, made this Avenue an attractive area for an industrial concentration and, subsequently, commercial, generating changes in the manner of use, which made it lose its eminently

\footnotetext{
${ }^{1}$ Licenciada em História e mestranda em Arquitetura e Urbanismo, Universidade Federal da Paraíba - UFPB. maiara_bello@hotmail.com

2 Professora do Departamento de Geociências e do Programa de Pós-Graduação em Geografia e Arquitetura da Universidade Federal da Paraíba e Pesquisadora do CNPQ. doralicemmaia@hotmail.br
} 
Revista Nacional de

Gerenciamento de Cidades

residential characteristic. Because of these changes, there was the need for the displacement of the population who lived along the avenue that, along with groups of people coming from various regions of the State seeking inclusion in new jobs, they started to inhabit other areas of the city, causing, among other factors, its territorial expansion. This way, the changes occurred in this avenue resulted to a new configuration and structure for the city of Bayeux. Thus, understand how interventions performed in Liberdade Avenue transformed the urban structuration of the city is the goal of this research.

KEYWORDS: Liberdade Avenue, Bayeux-PB, Urban Expansion.

\section{AVENIDA LIBERDADE: INFLUENCIAS EN LA ESTRUCTURA DEL ESPACIO URBANO BAYEUX - PB}

\section{RESUMEN}

La Avenida Liberdade, ubicada en la ciudad de Bayeux, se estableció como un eje estructural de su expansión urbana, con énfasis en el período comprendido entre las décadas de 1960 a 1980. Esto período está marcado por la emancipación política de la ciudad y por intervenciones de los grupos del sector privado que, junto con acciones específicas del gobierno, hicieron de esta Avenida una zona atractiva para la concentración industrial y, posteriormente, comercial, generando cambios en la forma de utilización, que la hizo perder su característica eminentemente residencial. Debido a estos cambios, ocurrió hubo la necesidad de desplazamiento de la población que vivió a lo largo de la avenida, junto con grupos de personas procedentes de diversas regiones del Estado que buscam inclusión en nuevos puestos de trabajo, que ahora habitan otras zonas de la ciudad, causando entre otros factores, su expansión territorial. Por lo tanto, los cambios ocurridos en esta avenida llevaron a una nueva configuración y estructuración. Así, entender como las intervenciones realizadas en la Avenida Liberdade transformarón la estructura urbana de la ciudad es el objetivo de esta investigación.

PALABRAS CLAVE: Avenida Liberdade, Bayeux-PB, Expansión Urbana.

\section{INTRODUÇÃO}

No processo da urbanização, a rua manifesta-se em elevado grau de importância, despontando através de suas formas ou usos. A partir dela, é possível perceber as características intrínsecas de um determinado espaço urbano, bem como as transformações ocorridas ao longo do seu processo histórico. Por meio da rua, a cidade se revela e, assim, se expressa como elemento central da vida urbana (CARLOS, 2001).

As ruas são espaços públicos que ligam diferentes pontos e locais de uma cidade, podendo algumas alcançar maior destaque em relação a outras. As mais 


\section{Revista Nacional de}

destacadas são usualmente classificadas como avenidas que, na maioria dos casos, são vias largas e com grandes extensões físicas, possibilitando a ligação a outras vias, ruas, bairros ou cidades. Algumas ainda possuem destaques em diferentes setores: comercial, turístico, cultural ou histórico, em relação ao local no qual se inserem.

Nesse sentido, estudamos a rua, particularmente a Avenida Liberdade, no município de Bayeux-PB, com suas singularidades, particularidades e universalidades, salientando os elementos cruciais que levaram a sua produção e consolidação como principal via de expansão para a cidade onde está inserida. Tal premissa advém de fatores que condicionaram a sua ocupação e as mudanças em sua forma de uso. Dessa forma, o entendimento das intervenções instauradas nessa rua tornou-se de grande importância para a compreensão de sua influência para o município.

Assim, definimos o objeto de estudo - Avenida Liberdade - e o recorte temporal correspondente ao período compreendido entre 1960 e 1980. Tais opções se deram em função do principal objetivo da pesquisa: analisar as transformações ocorridas na avenida durante as décadas supracitadas. Destarte, foram definidos os seguintes objetivos específicos: i) verificar as alterações na forma de uso do solo durante o recorte temporal da pesquisa - área residencial $x$ área industrial/comercial; ii) averiguar as repercussões dessas alterações na avenida para a expansão urbana da cidade de Bayeux.

A Avenida Liberdade sofreu alterações em relação à forma de ocupação e de usos, influenciando a maneira como as pessoas se relacionavam com ela. No início da década de 1960, se configurava como uma via eminentemente residencial, apresentando-se também como principal elo entre a capital e o interior do Estado, sendo ainda ponto de passagem para os estados vizinhos (Figura 01).

Paulatinamente, essa realidade começou a ser alterada, uma vez que a avenida sofreu modificações com a instalação e o início do funcionamento de várias indústrias (principalmente as que trabalhavam com o beneficiamento da fibra de 


\section{Revista Nacional de}

Gerenciamento de Cidades

sisal), seguidas por um comércio disposto linearmente ao longo do seu percurso, o que acabou por influenciar o crescimento gradativo da cidade. Em consequência disso, a Avenida se fortaleceu, tornando-se marco no processo de expansão da cidade, através das alterações de sua forma de uso, bem como exercendo influências no cotidiano daqueles que a frequentavam.

A partir da década de 1960, podemos perceber uma mudança na relação socioespacial da Avenida Liberdade, que gerou consequências no município, através da influência de fatores como a emancipação política e as transformações de usos da Avenida, quando deixa de apresentar um caráter residencial e passa a exibir um maior número de indústrias e, por conseguinte, intensifica-se a atividade comercial ao longo do seu percurso.

Baseados nesses aspectos, verificamos que as mudanças ocorridas na Avenida Liberdade apresentaram consequências para a cidade de Bayeux, com ênfase no seu processo de expansão urbana. Logo, a escolha desse tema considerou os seguintes aspectos: a necessidade de aprofundamento de estudos sobre essa avenida; a sua importância histórica, pois representa um marco para Bayeux, uma vez que sua formação induziu a constituição dessa cidade; a relevância desta via na estruturação da cidade; e o grande valor dos estudos das alterações socioespaciais e de intervenções como forma de analisar o processo de expansão urbana.

Diante dessas considerações, surgiu a preocupação em estabelecer o tema desse artigo de maneira a comportar a análise das transformações ocorridas nessa avenida durante o período delimitado, na perspectiva de ressaltar as suas mudanças de uso como elemento indutor dessas alterações, influenciados diretamente pela iniciativa privada (as indústrias) e pelo aparato estatal. Assim, partimos da seguinte hipótese: as alterações de uso da Avenida Liberdade entre os anos de 1960 e 1980 provocaram mudanças na estrutura urbana da cidade de Bayeux.

O presente artigo, intitulado "Avenida Liberdade: influências para a estruturação do espaço urbano de Bayeux - PB", é parte do trabalho desenvolvido 
Revista Nacional de

Gerenciamento de Cidades

durante o curso de mestrado em Arquitetura e Urbanismo da UFPB. Para tanto, o artigo se estrutura da seguinte forma: inicialmente, apresentamos o objeto de estudo e, em seguida, tratamos dos procedimentos metodológicos. Sequencialmente, trazemos a discussão sobre os conceitos de expansão urbana e intervenções privadas ou estatais no meio urbano e apresentamos com mais ênfase o recorte de estudo: a Avenida Liberdade e suas influências na expansão urbana de Bayeux. Por fim, tecemos considerações sobre o estudo, salientando que a pesquisa ainda se encontra em desenvolvimento.

\section{RECORTE DE ESTUDO: AVENIDA LIBERDADE}

A Avenida Liberdade articula fatores e elementos de várias ordens e importância para o município em que está inserida. Suas características históricas, sociais e econômicas perpassaram sua influência por toda a cidade, transformandoa na principal e mais importante via de Bayeux. Trata-se do maior eixo de articulação e ligação urbana entre várias áreas da cidade, via de passagem e elo de distribuição de fluxo entre alguns bairros e as cidades vizinhas. A sua relevância se dá ainda por constituir um espaço público de multifunções, sendo aglutinadora dos principais comércios e serviços de maneira bastante intensa.

Dessa forma, ao buscarmos o entendimento das transformações da Avenida que culminaram com o estabelecimento de uma nova forma urbana de Bayeux, torna-se imprescindível um estudo mais direcionado sobre ela, no intuito de compreender como se estabeleceram o jogo de interesses e a lógica produtiva que a transformaram ao longo do tempo.

Para iniciarmos, sabemos que, de maneira geral, entre as causas que contribuíram para o crescimento da cidade de Bayeux estão: a industrialização, que fez crescer a urbanização em determinados eixos da cidade; o uso do solo, quanto à importância das localizações e a produção de acessibilidade como determinantes do crescimento e da ocupação; e políticas públicas referentes às diretrizes de uso do 


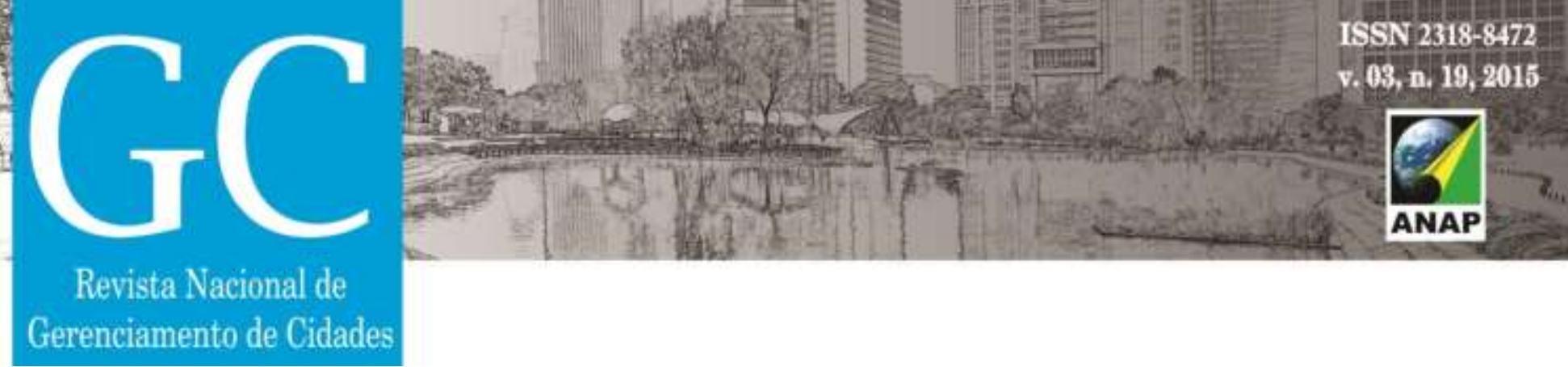

solo, quer sejam com fins industriais, comerciais ou de moradia. A nossa intenção aqui é demonstrar as influências que a Avenida gerou para tais elementos.

A Avenida Liberdade trata-se de uma rodovia estadual - a PB-004 - que possui aproximadamente $4.5 \mathrm{~km}$ de extensão, localizada no município de Bayeux, atravessando-o em seu sentido leste/oeste. Esse município apresenta uma extensão territorial de $32 \mathrm{~km}^{3}$, é margeado pelo Rio Sanhauá e estabelece divisa com João Pessoa e Santa Rita - PB, com as quais se interliga através da PB-004 e das BR 230/101 (Figura 01).

Figura 01: Localização do município de Bayeux no estado da Paraíba e da Avenida Liberdade.

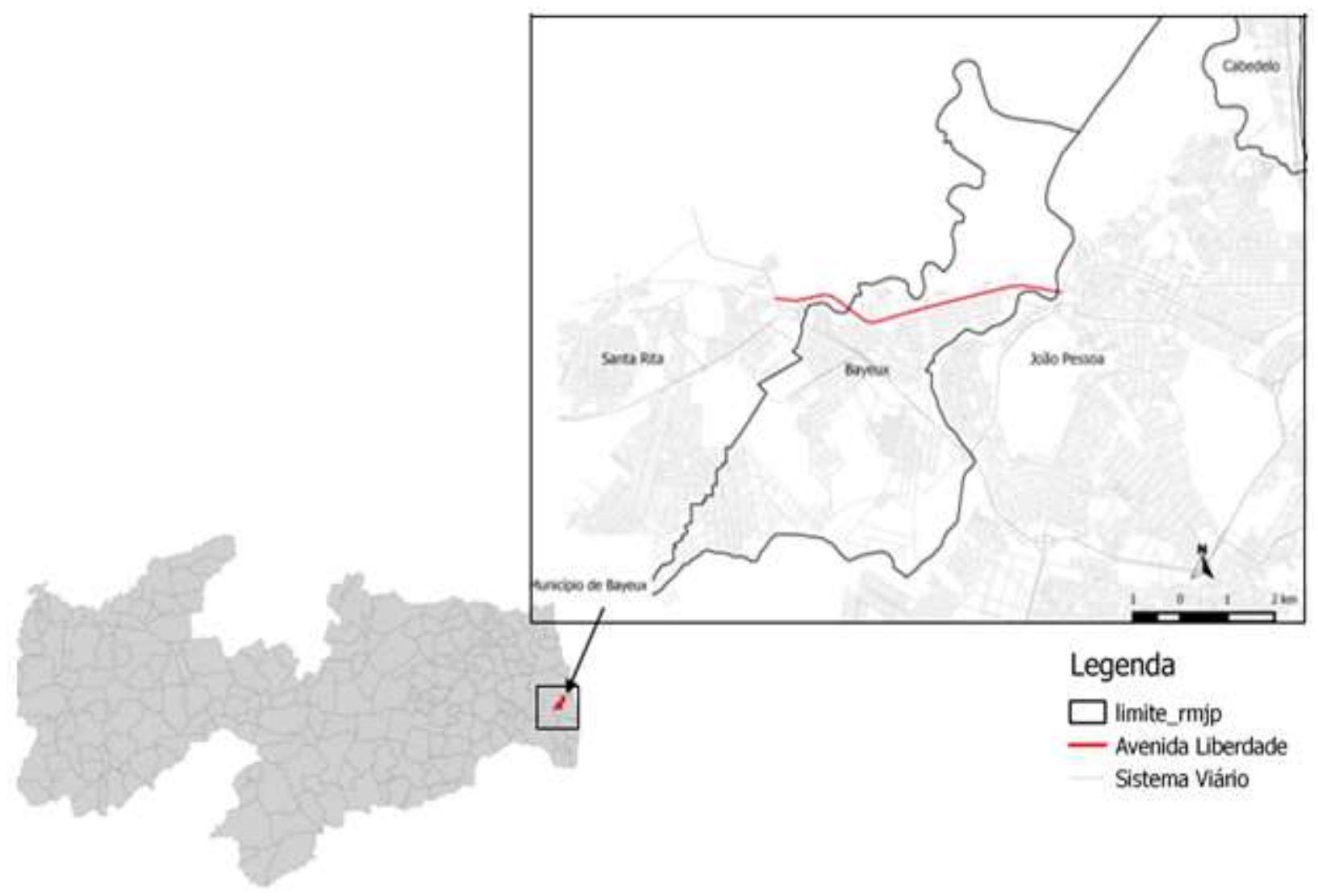

Fonte: Mapa Do Estado da Paraíba e Mapa Urbano do município de Bayeux - Fonte: Secretaria de Planejamento - Setor de Geoprocessamento - PMBY, editado por Alexandre Castro, 2015.

${ }^{3} \mathrm{O}$ seu diminuto território o torna um dos menores municípios do Estado da Paraíba. 


\section{Revista Nacional de}

Essa Avenida sempre teve um papel preponderante na cidade e, no que concerne a sua expansão, desenvolveu influência determinante. Foi se estruturando como uma estrada de ligação, caracterizando-se como um atrativo para o povoamento, o que a fez se fortalecer como eminentemente residencial, concentrando famílias com melhores rendimentos financeiros e, posteriormente, como industrial e comercial.

\section{PROCEDIMENTOS METODOLÓGICOS}

O trabalho tem como referência as transformações de uso na Avenida Liberdade no período de 1960 a 1980. Por se tratar de uma via que traz consigo o trajeto histórico da cidade, partiu-se do entendimento de que aquela se constitui como via norteadora das transformações urbanas, territoriais e sociais ocorridas em Bayeux. Dessa maneira, para alcançar os objetivos propostos na pesquisa, inicialmente escolhemos o método embasado na história, pois compartilhamos com a ideia de A. Rossi (2001, p. 193) de que "o método histórico é capaz de oferecer a verificação mais segura de qualquer hipótese sobre a cidade; a cidade é por si mesma, depositária de história".

Assim, estudamos a Avenida Liberdade subsidiada por um aporte histórico, bibliográfico, documental e cartográfico, aliado aos relatos daqueles que a vivenciaram no período estudado. Dessa maneira, construímos um referencial teórico-conceitual que tratou de temas como a estruturação e expansão urbana, voltando os olhares para Bayeux, de maneira a contribuir para a discussão, compreensão, identificação e caracterização não só da Avenida, mas das influências geradas por ela para o município.

Em relação às especificidades do objeto de estudo, buscamos o apoio de pesquisas em torno do processo histórico e de formação de Bayeux, que serviram de referências para o estudo da Avenida Liberdade. Ao longo da pesquisa, sentimos a necessidade de buscar aporte através de outras possibilidades. Nesse sentido, a História Oral revelou-se como rica fonte de subsídios para o desenvolvimento deste 
Revista Nacional de

Gerenciamento de Cidades

trabalho, complementando os documentos tidos como oficiais. Através dos relatos de pessoas que viveram na Avenida Liberdade no período estudado, seja através da moradia, trabalho, estudo ou passagem, foram adquiridas informações que lançaram luz sobre os acontecimentos ocorridos no período aqui delimitado.

Após as entrevistas e o contato com pessoas que viveram nesse período, conseguimos informações que, até então, não tinham sido trabalhadas, como a identificação da Avenida como corredor da Morte; avenida de trânsito confuso; coração da cidade; formas de utilização diferenciadas ao longo do seu percurso; área dos ricos $x$ área dos pobres; entre outras expressões proferidas pelos participantes.

Outra etapa foi a das análises fotográficas, pois a fotografia neste trabalho é entendida como um fato social, um documento (LE GOFF, 1990), servindo de perpetuadora da história dos indivíduos e da sociedade, da memória coletiva, desvendando várias faces do passado muitas vezes não tratadas pela história tida como "oficial". Para nós, a fotografia é uma fonte histórica se considerada como parte da realidade, um fragmento do passado envolvido em uma subjetividade de registro do autor que a concebeu.

Enfim, as junções das informações bibliográficas, documentais, fotográficas e cartográficas, somadas principalmente aos resultados das pesquisas de campo, viabilizaram a compreensão da dinâmica da Avenida Liberdade nesse período, possibilitando a redação deste trabalho e da dissertação que se encontra em andamento.

\section{INTERVENÇÕES NA AVENIDA LIBERDADE E AS CONSEQUÊNCIAS PARA O ESPAÇO URBANO DE BAYEUX}

A configuração da Avenida Liberdade no espaço urbano como via principal e eixo de ligação entre capital e interior fizeram-na um importante elemento do espaço intraurbano de Bayeux. Seu traçado quase linear e a boa acessibilidade, aliada à 


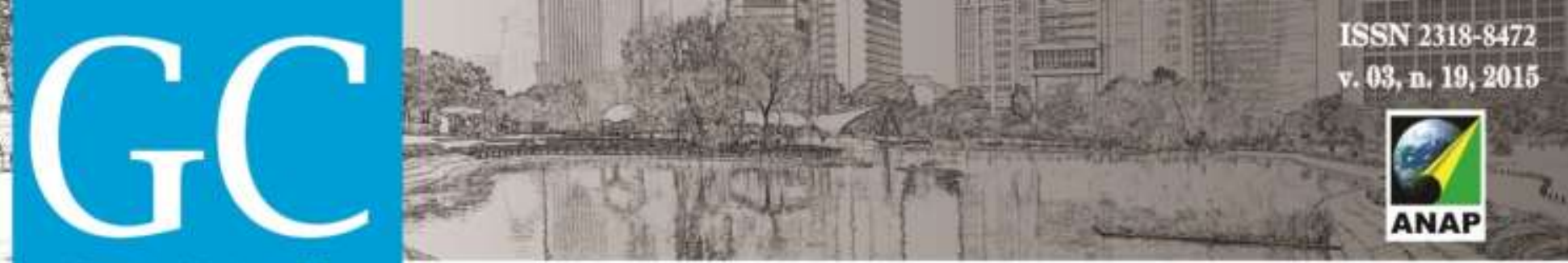

Revista Nacional de

Gerenciamento de Cidades

ferrovia e grandes lotes, condicionaram a atração dos interesses de diversos agentes, principalmente da iniciativa privada, que despertaram a atração para novos usos, quer fossem industriais, comerciais ou de prestação de serviços. Essa atração Ihe causou uma série de alterações, dentre as quais o forte impacto nas formas de utilização e ocupação do solo, na conformação da paisagem, bem como na vida cotidiana da população que foi inserida em uma nova configuração. Desse modo, a Avenida se fortaleceu enquanto elemento chave para a reordenação da estrutura urbana da cidade.

Verificar como se transformaram os usos nessa região nos traz um suporte para a compreensão das alterações de expansão geradas para todo o município. Ao falarmos em uso do solo, estamos relacionando-o às atividades que ocorrem em um determinado espaço da cidade, como bem assinala Capel (2002), para o qual o uso do solo é o resultado que corresponde às atividades que sobre ele se concretizam. Assim, percebemos que as mudanças de uso do solo ao longo da Avenida se deram de maneira muito intensa após a ocupação industrial, que foi seguida pela comercial.

A instalação das indústrias do beneficiamento da fibra natural do sisal foi um ponto de partida para as mudanças de uso na Avenida Liberdade que, ao ocuparem grandes lotes nas duas margens ao longo do seu percurso (Figura 02), acarretaram influências para todo o município. Carlos (1988) explica que a concentração industrial em uma mesma área é uma prática comum, reflexo da "economia de aglomeração". Ao se concentrarem em uma área próxima, formam o suporte necessário para o seu funcionamento, uma vez que itens de infraestrutura, mão de obra, proximidade de indústria complementares, mercado diversificado e redução dos custos da produção são estabelecidos em seus entornos. 


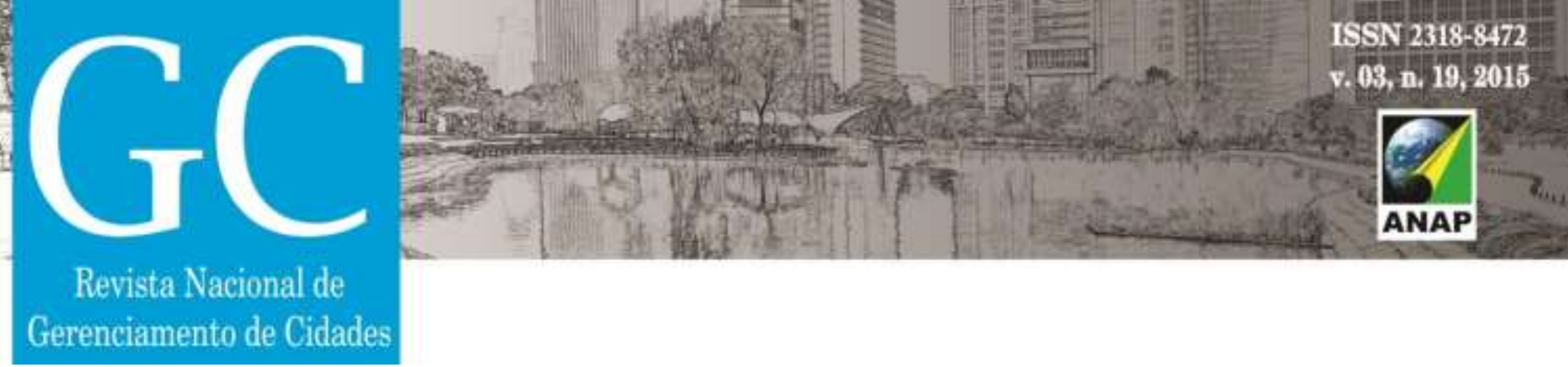

Figura 02: Localização das indústrias ao longo da Avenida Liberdade - Bayeux/PB.

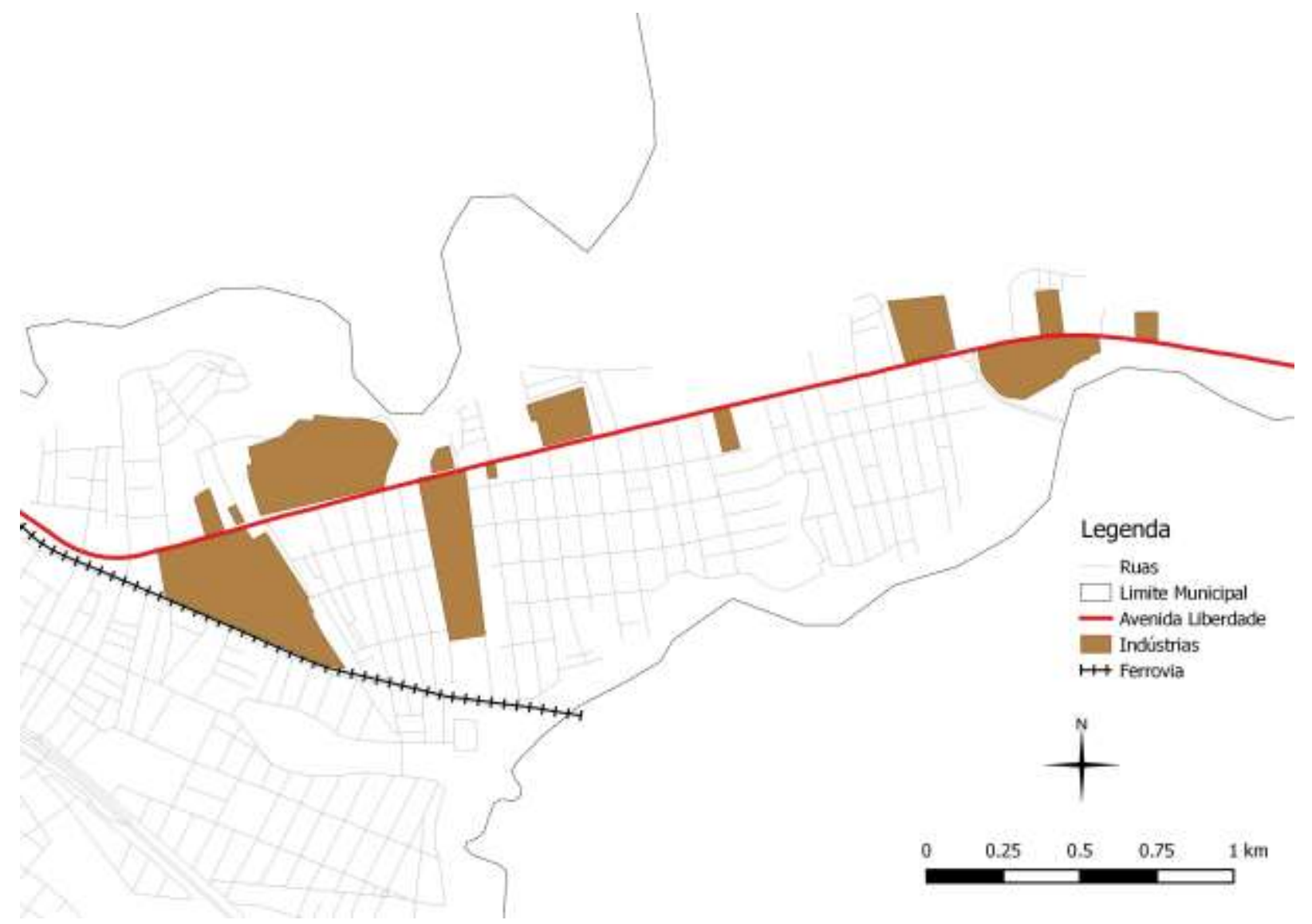

Fonte: Mapa Urbano de Bayeux - Secretária de Planejamento - Setor de Geoprocessamento - PMBY, editado por Alexandre Castro, 2014.

Dessa forma, a concentração industrial nessa área foi atraindo outras indústrias e comércio, o que transformou o espaço e modificou os fluxos dos recursos e de mão de obra, além de reconfigurar a paisagem para garantir a satisfação de uma série de necessidades que ultrapassaram os espaços e edificações físicas. Itens como energia elétrica, serviços de apoio à produção, escritórios, rede de comunicação e transportes, e demais aparatos, foram sendo instalados com o apoio do estado. Contudo, na contramão das benesses, essas 
Revista Nacional de

Gerenciamento de Cidades

indústrias socializaram desvantagens com a população e com a cidade como um todo, através da poluição, congestionamentos e ocupação de grandes lotes.

Conforme a atividade industrial foi se solidificando e adquirindo importância no núcleo antigo da cidade, a densidade demográfica alcançou números expressivos ${ }^{4}$, pois a procura por postos de trabalho nessas indústrias transformou Bayeux em área bastante atrativa. Por consequência, outra importante alteração foi a expansão territorial, que gerou modificações em toda a estrutura urbana do município, uma vez que a "produção em grande escala, com grande número de empregados, pressupõe a concentração da população e do próprio capital em determinados pontos." (CARLOS, 1988, p. 36-7), quer seja através de ações do governo, da iniciativa privada ou da própria população.

Dessa forma, as áreas de fixação da população aumentaram e as distâncias físicas marcaram as relações do poder aquisitivo da população, que era articulada segundo os novos interesses, ao mesmo tempo em que era subordinadora em relação à localização do espaço. Grupos sociais de rendimentos mais altos se deslocaram para uma área mais distante que, até então, era a habitual, enquanto os mais pobres se fixaram em regiões deterioradas, de alta vulnerabilidade ambiental, dentre as quais estão as regiões ribeirinhas e de manguezal ou áreas consideradas de risco, tais como as situadas próximas à linha férrea, que se localizava em paralelo à Avenida. Sendo assim, a estratificação do uso do solo em conformidade com as condições financeiras das classes que o ocupavam se estabeleceu de maneira bem marcada.

Para entendermos a especialização de determinada área enquanto seletividade de lugar para a fixação de grupos sociais específicos, buscamos apoio em Villaça (2001), que trata a segregação social enquanto disputa de localização e conformidade com as exigências funcionais, que tornam certo ponto mais ou menos atrativo e, consequentemente, mais ou menos valorizado. Segundo o autor, para as

\footnotetext{
${ }^{4}$ Em Bayeux, segundo o IBGE, a população em 1960 era de 17 mil habitantes, em 1970, de 35.500 habitantes e, em 1980, essa população era de aproximadamente 60 mil habitantes.
} 


\section{Revista Nacional de}

Gerenciamento de Cidades

classes de melhores condições financeiras, são produzidos espaços com melhor acessibilidade e possibilidades de deslocamentos. Aos mais pobres, cabe a adequação econômica, buscando proximidade com o trabalho para garantir um menor deslocamento, terrenos mais baratos com estrutura precária ou mesmo a invasão de áreas do poder público. O fator localização favorece a nossa compreensão, reforçada por Villaça (2001), quando diz que o espaço urbano é constituído por um "estoque de recursos produzidos pelo trabalho humano. [...] as localizações - definidas em termos de possibilidades de deslocamentos espaciais do ser humano - representam possibilidades de deslocamentos desses recursos" (VILLAÇA, 2001, p. 354).

Assim, se faz necessário entender as transformações ocorridas na Avenida Liberdade, pautadas nas intervenções por parte da iniciativa privada e do Estado para, dessa forma, compreender as modificações urbanas ocorridas no município de Bayeux.

A grande concentração industrial e comercial ao longo da Avenida Liberdade, outrora área eminentemente residencial, criou para a população que nela residia, bem como para os que estavam chegando à cidade, a necessidade de novas áreas

para habitar. Nesse ínterim, a área mais periférica do município oferecia uma abundância de solos a preços relativamente baixos, principalmente se comparados aos mais próximos ao centro, além da relativa facilidade de acesso.

Com tais características, essa região passou a ser bastante procurada, ainda que em um primeiro momento não contasse com a infraestrutura básica de itens como água encanada, esgoto ou energia elétrica. Todavia, foi um período em que o parcelamento do solo aconteceu de modo intenso e desordenado. As prioridades daquela parte da população não refletiam preocupações futuras, como a preservação de espaços comunitários e a distribuição regular das áreas. Esse fato ocasionou reflexos posteriores, verificados através da não uniformização das quadras ou das vias de circulação, dos entroncamentos irregulares, ruas sem saídas, entre outros problemas. 


\section{Revista Nacional de}

Logo, ao se observar o município de Bayeux na transição das décadas de 1970 e 1980, principalmente se tomarmos como referência o seu centro, é possível perceber que as áreas disponíveis em seu entorno foram sendo sucessivamente ocupadas e configuradas de acordo com as funções que Ihes eram reportadas.

Ainda nesse período (década de 1970), começaram as ações governamentais direcionadas para a construção de maior volume de conjuntos habitacionais. O governo direcionou esforços para essa prática como "uma função política de tentar frear o processo de aguçamento dos conflitos sociais, particularmente os movimentos populares ligados à questão de moradia, que começava a tomar vulto em todo o território nacional" (LAVIERI, 1999, p.47).

Dessa maneira, a expansão territorial de Bayeux foi se moldando em conformidade com a reprodução do capital e dos interesses de alguns grupos. De um lado, estavam as indústrias ocupando grandes lotes na principal área da cidade e, do outro, encontrava-se o trabalhador que tinha a necessidade de morar em determinado lugar. É necessário deixar claro que a expansão urbana pode ocorrer de forma ordenada, embasada em regras previamente estabelecidas pelo aparato estatal através de estudos de viabilidade, ou espontânea, de acordo com a necessidade da população, como a que ocorreu em Bayeux. Nesse caso, como já exposto, resultou-se da participação de diversos agentes com intervenções direcionadas para que a organização do espaço garantisse benefícios para os seus interesses.

Em conformação com sua realidade, novos caminhos foram se espalhando e outros se fortalecendo como tentáculos que partiam da Avenida Liberdade. A circulação de automóveis e transportes de passageiros facilitou o acesso às áreas mais distantes. A Avenida Liberdade, com sua vocação polarizadora, delineada ao longo de sua estrutura linear de comércio e serviços, foi, aos poucos, ramificando a circulação e o acesso entre as várias áreas da cidade.

Pode-se, então, perceber que os modos de transportes e a configuração das vias também exerceram influências na expansão de Bayeux. Esse tipo de 


\section{Revista Nacional de}

Gerenciamento de Cidades

acontecimento pode ser ratificado através de Villaça (2001), quando afirma que ocorre uma relação entre as vias regionais de transporte e o crescimento físico das cidades.

O município passou a ser controlado pelos agentes privados em consonância com o aparato estatal que buscava viabilizar, através de suas ações, a acumulação do capital em seu favor. A estrutura urbana não foi nada mais que reflexo da movimentação do capital. As classes sociais mais abastadas passaram a se concentrar na região mais ao sul que, pouco tempo depois, foi destinada a obras de infraestrutura, como calçamento e esgotamento sanitário. Já as de menores condições financeiras seguiam de maneira irregular e em condições precárias.

Nesse momento da década de 1980, a ocupação do espaço urbano de Bayeux ia se consolidando, o que, além das consequências já citadas, Ihe fez substituir o uso agrícola e a ocupação das áreas vazias. Apresentava-se uma realidade em vias de definição: principalmente pela exiguidade territorial do município, grupos sociais de níveis de renda díspares se fixavam em regiões relativamente próximas, apesar de socialmente bem distantes.

Dessa forma, a maneira como a população se apropriou do solo urbano em Bayeux se realizou nitidamente de forma desigual, reproduzindo a característica da exclusão social embutida no processo de urbanização, que é comum na maioria das cidades. $\mathrm{O}$ crescimento da cidade foi acompanhado pelo aumento da quantidade de cortiços e de habitações precárias em paralelo às habitações de médio e alto padrão, assim como aos aparatos para as indústrias, comércio e serviços.

\section{CONSIDERAÇÕES FINAIS}

Mesmo com a impossibilidade de abordar todas as intervenções ocorridas na Avenida Liberdade através deste artigo, percebe-se que entender como se estabeleceu a configuração territorial de Bayeux foi importante para compreendermos a estruturação dos bairros e a concentração de pessoas em determinados lugares a qual, entre outros fatores, se ligou diretamente à 
Revista Nacional de

Gerenciamento de Cidades

concentração de renda daquele núcleo populacional. Nessa compreensão, podemos perceber que, em se tratando de autonomia e de deslocamento em relação à qualidade da prestação de serviços e equipamentos públicos, a região central era a mais abastecida. Todavia, nos locais onde as elites se instalaram, uma boa quantidade de serviços públicos e privados auxiliou a minimizar seus custos de deslocamentos, por exemplo. Esse é um tipo de conformação mostrado por Villaça (2001), para o qual quem possui maior poder aquisitivo localiza-se nos melhores locais da cidade em termos de acessibilidade. Dessa maneira, "o espaço urbano está continuamente sendo produzido e reproduzido", consistindo em produzir e reproduzir localizações melhores ou piores.

A produção e consumo do espaço urbano nada mais são, em última instância, do que a destinação de melhores ou piores condições, a produção e consumo de localizações, ou seja, acessibilidades que, por sua vez, se produzem de maneira dupla: "em primeiro lugar, durante a própria produção/consumo do espaço, isto é, dos pontos a serem interligados. Em segundo lugar, pela atuação sobre o sistema de transporte que une os pontos produzidos a serem interligados. $\mathrm{Na}$ área onde tendem a se segregar as altas camadas de renda as localizações se produzem e consomem por e para um determinado sistema de transporte: aquele baseado no automóvel. No restante da cidade, elas se produzem e se consomem pelo e para o transporte público, com toda a sua precariedade, quando não para os deslocamentos a pé". (VILLAÇA, 2001, p. 356)

Essas reflexões demonstram que o processo de produção do espaço urbano de Bayeux, partindo da década de 1960, se estabeleceu diretamente atrelado às modificações ocorridas na Avenida Liberdade, principalmente se levarmos em consideração a ocupação em níveis residenciais. Foi possível perceber a dispersão e a descentralização dessas áreas, que passaram a ser estabelecidas de maneira distante e descontínua territorialmente em relação ao centro tradicional. Além disso, podemos ressaltar as transformações atreladas aos usos e às funções, como ocorridas na Avenida, que passou a ser região industrial e comercial. Dessa forma, 
Revista Nacional de

Gerenciamento de Cidades

compreender os componentes históricos e condicionantes da estruturação urbana possibilitou o entendimento em torno de uma parte dos processos que atuaram e, de certa maneira, ainda atuam no espaço urbano de Bayeux.

\section{REFERÊNCIAS}

CAPEL, Horácio. La morfología de las ciudades. I. Sociedad, cultura y paisaje urbano. Barcelona: Ediciones del Serbal, 2002.

CARLOS, Ana Fani Alessandri. Espaço e indústria. São Paulo: Contexto, 1988.

Espaço e tempo na metrópole. São Paulo: Contexto, 2001.

A cidade: $O$ homem e a cidade. A cidade e o cidadão. De quem é o solo urbano? 8. ed. São Paulo: Contexto, 2005

O espaço urbano: novos escritos sobre a cidade. São Paulo: FFLCH, 2007.

CORRÊA, R. L. O espaço urbano. 4. ed. São Paulo: Editora Ática, 1989.

GIL, Antonio Carlos. Métodos e técnicas de pesquisa social. 5. ed. São Paulo: Atlas, 1999.

LAVIERI, João Roberto; LAVIERI, Maria Beatriz Ferreira. Evolução urbana de João Pessoa pós-60. In: GONÇALVES, Regina Célia; LAVIERI, João Roberto; LAVIERI, Maria Beatriz Ferreira; RABAY, Glória. A questão urbana na Paraíba. João Pessoa: Ed. Universitária / UFPB, 1999. (Coleção Histórica Temática da Paraíba; v.3)

LAMAS, José Manuel Ressano Garcia. Morfologia urbana e desenho da cidade. Fundação Calouste Gulbenkian, 1993.

LEFEBVRE, Henri. Direito à cidade. São Paulo: Centauro, 2001.

A revolução urbana. Belo Horizonte: Ed. UFMG, 2008.

LE GOFF, Jacques. História e memória. Campinas, SP. Editora da UNICAMP, 1990.

MAIA, Doralice Sátyro. A morfologia urbana no movimento da modernidade. In: X ENCONTRO DE GEÓGRAFOS DA AMÉRICA LATINA, 2005, São Paulo. Anais eletrônicos... São Paulo: Universidade de São Paulo, $2005 . \quad$ Disponível em: http://observatoriogeograficoamericalatina.org.mx/egal10/Procesosambientales/Geomorfologia/04.pdf. Acesso em: 30 jun. 2015.

Lotes e ruas: componentes para análise da produção dos loteamentos fechados. In: SPÓSITO, Eliseu Savério; SPOSITO Maria da Encarnação Beltrão; SOBARZO, Oscar (organizadores). Cidades médias: produção do espaço urbano e regional. 1. ed. São Paulo: Expressão Popular, 2006, p.155 -173. 
MEDEIROS, Coriolano. Dicionário corográfico do Estado da Paraíba. Ministério da Educação e Saúde. Rio de Janeiro: Departamento de Imprensa Nacional, 1950.

OLIVEIRA, Ariosvaldo Alves de. Bayeux: seu povo, sua história. João Pessoa: A União, 1999.

Calendário comemorativo de Bayeux. João Pessoa: Potiguaras , 2012.

ROSSI, Aldo. A arquitetura da cidade. 2. ed. São Paulo: Martins Fontes. 2001.

VILLACA, Flávio. Espaço intra-urbano no Brasil. São Paulo: Studio Nobel: FAPESP: Lincoln Institute, 2001. 